\title{
On the permissibility of shaping children's values
}

Andrée-Anne Cormier, Law Department, Universitat Pompeu Fabra, Barcelona, Spain andreeanne.cormier@upf.edu

Forthcoming in Critical Review of International Social and Political Philosophy

\begin{abstract}
According to Harry Brighouse and Adam Swift, parents have a limited and conditional moral right to deliberately shape their children's values and interests in light of their own particular comprehensive convictions. Their view contrasts with Matthew Clayton's account of legitimate childrearing, according to which it is always impermissible for parents to seek to pass on their particular convictions to their children or, more generally, to 'enroll' them into their conception of the good, since this violates a requirement of respect for children's independence. This paper offers a novel defense of Brighouse and Swift's position that at least some forms of comprehensive enrolment are permissible. First, I argue that the claim that there is a duty to respect the independence of very young children is problematic. Then, drawing on Brighouse and Swift's account of familial relationship goods, I argue that seeking to pass on comprehensive values or beliefs to one's children is actually compatible with proper respect for their independence, as Clayton understands it.
\end{abstract}

Keywords: parental duties; parent-child relationship; shaping values; comprehensive enrolment; religious upbringing; children's autonomy; children's independence.

\section{Introduction}

This paper examines the issue of whether it is morally acceptable for parents to deliberately shape their children's values or ends, according to their own particular convictions. In their 
important book, Family Values: The Ethics of Parent-Child Relationships (2014), Harry Brighouse and Adam Swift argue that parents have a limited moral right to intentionally shape their children's particular values and interests in light of their own - provided that this is conducive to meeting children's most fundamental interests, which crucially include the development of their capacities for autonomy and for a sense of justice. Their view contrasts with Matthew Clayton's well-known account of legitimate childrearing (2006, 2012, 2015), according to which it is always impermissible for parents to deliberately seek to instill in their children particular beliefs on so-called 'comprehensive' issues, such as 'religion, occupation, lifestyle, and sexuality' (Clayton 2012, p. 353). Contrary to Brighouse and Swift, Clayton believes that parents have no right (not even a limited and conditional right) to deliberately encourage their children to endorse specific controversial beliefs about what activities are worth pursuing, what is valuable, how to live or how to conceive the world. More generally, he thinks that it is always morally wrong for parents to 'comprehensively enroll' their children into a conception of the good or worldview, such as any religious view. This implies, for instance, that it is impermissible for parents 'to baptise their child or include her within religious ceremonies' (Clayton 2012, p. 362). ${ }^{1}$

One important source of disagreement between Brighouse and Swift, on the one hand, and Clayton, on the other, concerns the issue of how to understand parents' duties regarding children's autonomy. Clayton believes that parents have a duty to facilitate the development of their children's autonomy, understood as an 'end-state' or as an 'achievement', that is, as the possession and exercise of a capacity to rationally form, revise, and pursue some particular goals, in a context characterized by a sufficiently rich set of alternatives. But parents also have a separate duty to respect their children's autonomy 
as 'independence' (henceforth, simply 'independence'), where the latter is a matter of not having others decide for oneself which ends to pursue. Brighouse and Swift seem to oppose the idea that there is a duty to respect children's independence (2014, p. 170), at least as Clayton understands it. However, in their book they do not present in detail their reasons for their skepticism. Yet, the issue is important. In fact, according to Clayton, the duty to respect children's independence provides the strongest reason for rejecting comprehensive enrolment. If so, it also provides a direct challenge to Brighouse and Swift's position.

My main goal in this paper is to take up Clayton's important challenge and propose a novel defense of the view that at least some forms of comprehensive enrolment are morally permissible. In particular, my aim is to provide new support for Brighouse and Swift's position by showing, first, that the claim that there is a duty to respect the independence of very young children is questionable and, second, by arguing that the requirement to respect children's independence, as Clayton understands it, does not in any case support his conclusion that comprehensive enrolment is always impermissible. Rather, it supports the view that some forms of comprehensive enrolment, namely, those that promote autonomyas-achievement, are, all other things equal, morally permissible. ${ }^{2}$

The paper is structured as follows. I will start by examining, and rejecting, Clayton's first argument against comprehensive enrolment, i.e. the argument from the cost of rejection. According to it, comprehensive enrolment is impermissible because it makes children's later revision or abandonment of their parents' conception of the good emotionally too costly and, as such, undermines autonomy. I will argue that neither of the two most plausible ways of conceiving the relationship between the emotional costs of revision and 
autonomy supports the conclusion that all forms of comprehensive enrolment are impermissible. I will then reconstruct, and raise doubts about, Clayton's second argument against comprehensive enrolment, which appeals to his idea of respect for independence. According to it, comprehensive enrolment is impermissible because, insofar as parents cannot reasonably expect their children to retrospectively consent to being enrolled into a particular conception of the good upon reaching adulthood, it violates children's independence. I will argue that Clayton's defense of his principle of retrospective consent is unconvincing, since it overlooks a morally significant difference between two ways in which an individual can lack a 'capacity for autonomy'. I will consider different possible understandings of the principle of retrospective consent. Drawing on Brighouse and Swift's account of familial relationship goods, I will show that at least some forms of comprehensive enrolment can actually pass what seems to be the most plausible test of respect for children's independence, namely, what I call the 'anti-perfectionist test of retrospective consent'. Finally, I will consider, and rebut, an important objection concerning the aim of parents who seek to shape their children's values.

\section{Preliminaries}

Before proceeding to a critical assessment of Clayton's view, it is worth presenting the three main premises around which the liberal debate over comprehensive enrolment is centered. These premises explain why many liberal philosophers writing on familial justice, like Clayton as well as Brighouse and Swift, think that comprehensive enrolment raises difficult ethical questions. 
The first, and most basic, premise is that children have an independent moral status. They are not their parents' property and have fundamental interests of their own. In fact, some of their interests are weighty enough to ground the attribution of moral rights to them as well as corresponding duties on the part of others. The second premise is that the parent-child relationship is non-voluntary and coercive for children. The latter cannot escape or consent to being in a relationship with their parents. This relationship is thus authoritative and coercive in nature. This explains why the deliberate shaping of children's values can be seen as prima facie more morally troubling than adult-to-adult 'value-shaping' (or 'valueinfluencing') - to use Brighouse and Swift's expressions. The reason is that, unlike most adults, children do not typically have the capacity to select or leave their intimate relationships and to reflect autonomously on the influence that others exercise on them. In addition, shaping children's values is a special kind of exercise of authority over them, namely, one that has a profound influence on their lives. This is in fact the third premise framing the debate. ${ }^{3}$ Values are special because they are identity-defining. They govern people's ends. They are part of what makes persons who they are. So, shaping a child's values appears to be much more significant, morally speaking, than other exercises of parental authority, such as, e.g., the choice of making one's child eat pasta rather than rice for dinner. ${ }^{4}$

Given that children are independent moral beings, and that shaping their values potentially implies shaping how they will aspire to live, in a coercive manner and without their autonomous consent, the question arises as to whether, why, and to what extent, comprehensive enrolment is morally permissible. For his part, Clayton maintains that comprehensive enrolment is never permissible. In the next sections, I will examine, and 
reject, the two main arguments offered by Clayton in favor of this conclusion: the argument from the cost of rejection and the argument from retrospective consent.

\section{The argument from the cost of rejection}

Clayton's first argument states that comprehensive enrolment renders the rational revision or abandonment of one's parents' conception of the good emotionally too costly, in a way that undermines one's ability to rationally pursue alternative goals (Clayton 2006, p. 106107). ${ }^{5}$ Clayton does not deny that it can be psychologically difficult to reject one's parents' conception of the good also for individuals who have not been 'enrolled into it'. This is because the ideals and practices that a child is exposed to during childhood always have significant 'emotional grip' - perhaps especially when they are her parents' identifydefining beliefs. However, Clayton believes that comprehensive enrolment exacerbates the emotional costs of revising or rejecting one's parents' beliefs, up to the point of undermining one's ability to opt for a different conception of the good. To be sure, Clayton recognizes that comprehensive enrolment is compatible with the development of the capacities required for autonomy-as-achievement. Still, he thinks that comprehensive enrolment generates psychological costs of rejection so high as to impair one's disposition and aptitude to effectively endorse values, and pursue aims, different from those of one's parents, in accordance with one's own rational judgment. In other words, he thinks that comprehensive enrolment undermines one's ability to exercise autonomy, by adopting and pursuing goals that one rationally finds more plausible and attractive. ${ }^{6}$ 
In order to properly assess this argument, it is useful to begin with the following question. How exactly should we envisage the relationship between autonomy and the emotional cost of rejection? The argument seems to point to two possibilities. The first is that, above a certain threshold of emotional cost, a person is unable to exercise autonomy and counts thereby as non-autonomous. Let us call this 'the threshold view'. The second possibility is that the higher the emotional cost, the less is a person able to exercise autonomy and, as such, the less autonomous she is. Let us call this 'the degree view'.

Consider the threshold view. In order for the claim that comprehensive enrolment is always impermissible to hold, it must be the case that all instances of comprehensive enrolment impose such a high emotional cost of rejection on the child that she becomes unable to exercise her autonomy. However, this seems implausible. In fact, Clayton himself seems to recognize this, for he simply talks about the psychological difficulty of rejecting one's parents' beliefs as a result of comprehensively enrollment. Clayton also explicitly recognizes that comprehensively enrolling a child is compatible with educating her 'such that later in life she can autonomously decide to continue with or reject the religion into which she has been enrolled' (Clayton 2015, p. 130). This is enough to conclude that, despite the fact that comprehensive enrolment may generate high rejection costs, it is not the case, even by Clayton's own lights, that such costs are always higher than the threshold required to prevent the future adult from exercising autonomy.

Consider now the degree view. To the extent that the ability to exercise autonomy is not linked to a specific level of emotional cost, this view seems to avoid the objection raised against the threshold view. However, the argument based on the degree view presents two 
other problems. First, it does not seem to be the case that comprehensive enrolment always generates higher emotional costs of rejection and, thereby, a lower degree of autonomy, than non-comprehensive educational approaches. Indeed, as pointed out by Brighouse and Swift (2014, pp. 170-171), as well as by Cameron (2012, pp. 350-351), people enrolled into conceptions of the good that attribute great value to autonomy, such as liberal Anglicanism or secular humanist views, are not especially likely to find it very difficult to revise or even abandon their parents' comprehensive beliefs. Similarly, it is far from clear that abandoning one's parents' beliefs is always less emotionally costly for those who were not enrolled into a particular conception of the good. Children who were not enrolled into a conception of the good may still be very aware of what their parents' deepest convictions are, and may still fear disappointing their parents by not endorsing those convictions.

To illustrate this point, imagine two parents who attribute great value to art and artistic creativity as part of their conception of the good. The first parent deliberately tries to instill this view in her child, while the second does not (i.e. she tries to remain as neutral as possible about the value of art and artistic creativity in making educational decisions for her child). Suppose that both children eventually form the belief that art and artistic creativity have very little value, and that 'art-oriented' careers and goals are not worth pursuing. Is there reason to think that taking this stance will inevitably be emotionally more costly for the first child? The answer seems negative. A parent who refrains from comprehensively enrolling her child does not necessarily care less about what her child comes to believe. In fact, she might be as disposed as the first parent (e.g. because of her character or her especially deep identification with certain ideals) to be disappointed, and to let this transpire, if her child comes to endorse different values than her own (or assign them very 
different weight). Again, if that is true, it suggests that the emotional cost of rejection is determined by factors not necessarily related to comprehensive enrolment per se.

The second problem with Clayton's argument is that it is not clear whether the degree view itself is a plausible view of the relationship between emotional cost and autonomy. For one, the degree view seems to imply that not incurring any emotional cost when rejecting previously held views is a sufficient condition for a person to count as maximally autonomous. However, this claim is questionable. Indeed, as suggested above, abandoning a previously held conception of the good may be emotionally difficult for anyone, even for fully autonomous persons, since conceptions of the good are identify-defining. In fact, that it is emotionally difficult for a person to abandon her parents' conception of the good may in some cases indicate that that person was genuinely and autonomously committed to it.

The upshot is the following. Whether Clayton adopts the threshold view or the degree view of the relation between emotional cost and autonomy, his conclusion that comprehensive enrolment is always impermissible does not hold. Thus, Clayton's first argument is unpersuasive.

\section{The argument from retrospective consent}

The second, and most important, argument offered by Clayton - the argument from retrospective consent - holds that comprehensive enrolment is always impermissible because it is intrinsically autonomy-violating. This argument is best understood in light of Clayton's distinction between autonomy-as-achievement and autonomy-as-independence 
(2012). ${ }^{7}$ Recall that, according to the former, an autonomous person is one who possesses and exercises a capacity to rationally form, revise, and pursue some particular goals, in a context characterized by a sufficiently rich set of options. According to the latter, autonomy is a matter of not having others decide for oneself which ends to pursue, of not being forced or manipulated into pursuing some particular goals. As we have seen, Clayton thinks that individuals have an interest not just in setting goals for themselves, but also in not having others setting goals for them. That is, they have an interest not just in autonomy-asachievement, but also in independence.

The risk of violating independence is high when decisions are taken for individuals who are unable to decide for themselves. In order to assess whether independence is violated in such cases, Clayton proposes a test that appeals to the idea of retrospective consent whereby an individual's independence is violated if she cannot reasonably be expected to retrospectively consent to (or at least not reject) ${ }^{8}$ the decision that is made on her behalf. We can call this Clayton's 'principle of retrospective consent'. This principle is at the heart of Clayton's second argument against comprehensive enrolment.

Here is my reconstruction of the overall argument. ${ }^{9}$ The starting point is the claim that (1) there is a duty to respect each person's independence. Clayton holds that (2) the independence of a person who is unable to make autonomous decisions (in the achievement sense) is violated if she cannot reasonably be expected to retrospectively consent to the decision that is made for her. From (1) and (2), it follows that (3) the person in a position to decide for another who is unable to make autonomous decisions has a duty to decide for the latter person in light of reasonable expectations about her retrospective consent. Clayton 
claims that (4) when a person in a position to decide does not know the content of the other person's beliefs, she cannot reasonably expect that other person to retrospectively consent to being treated according to a particular conception of the good because she may turn out not to endorse that particular conception of the good. Thus, (5) if an individual decides to treat a person according to a particular conception of the good, she violates that person's independence.

According to Clayton, this line of thought applies directly to children. In fact, even though children are currently unable to make autonomous decisions, they will be able to do so in the future and thereby to retrospectively consent to or dissent from how they were treated. From (1), it follows that (1') there is a duty to respect children's independence. From (2), it follows that (2') children's independence is violated if they cannot reasonably be expected to retrospectively consent to the decisions that are made for them. From (3), it follows that (3') parents, who are in a position to decide for their children, have a duty to decide for them according to principles or ideals to which they can expect their children to retrospectively consent. From (4), it follows that (4') since parents do not know the content

of their children's future beliefs, they cannot reasonably expect them to retrospectively consent to being comprehensively enrolled. Hence, (5') when parents comprehensively enroll their children, they violate their independence. Therefore, from (1') and (5'), it follows that (6') the comprehensive enrolment of children is impermissible.

\section{Clayton's argument by analogy}

Clayton's most recent and most detailed attempt to defend the principle of retrospective 
consent when applied to children is by means of analogies designed to convince the reader that choosing for a non-autonomous child or infant, in a way to which she cannot reasonably be expected to retrospectively consent, does indeed violate her independence. ${ }^{10}$ He gives the following example:

Skin Graft plus Nose Job: Betty, who is an unknown visitor, is rendered unconscious by an accident and is having a skin graft to restore the damaged skin on her face. The doctor also sees that Betty's nose might be a more attractive shape and so fixes that as well. (Clayton 2012, p. 357)

Clayton suggests that Betty's situation is analogous to a child's situation in two important respects. The first is that Betty is unable to make autonomous decisions. The second is that the doctor does not know Betty's informed preferences, nor her conception of the good. The first point is true of children (or at least infants); the second of parents who have authority over them. According to Clayton, this example is important because, in Betty's case, we would clearly say that the doctor has done something wrong by deciding to fix her nose. More specifically, Clayton thinks that this wrong is captured by the idea of retrospective consent. His idea is that if respect for someone's independence requires getting her consent, which is surely highly plausible, respect for the independence of someone who is unable to make autonomous decisions requires deciding for her according to ideals, norms or principles that will most likely elicit her retrospective consent. In Betty's case, as Clayton puts it: 'When she returns to consciousness, we are almost certain that Betty will thank the surgeon for the skin graft, but far less confident that she will endorse the nose job' (Clayton 2012, p. 357). Importantly, if Betty's situation is relevantly 
analogous to a child's situation, then this example shows that a child's independence can similarly be violated when her parents decide for her according to ideals that she cannot reasonably be expected to retrospectively consent to.

I share the intuition that Betty's independence has been violated. I am also willing to accept the connection that Clayton establishes between independence and retrospective consent in this case. However, this does not commit us to accepting the view that young (or at least very young) children's independence is similarly violated when their parents decide for them without taking into account the retrospective consent requirement. The reason is that there is a morally significant disanalogy between Betty and a young child, which renders the application of the principle of retrospective consent more doubtful in the case of young children.

Let us start by presenting the disanalogy. Both Betty and a typical young child are unable to make autonomous decisions. In a sense, we can then say that both are unable to exercise autonomy (in the achievement sense). However, the sense in which this is true for each of them is different. Betty has an already developed capacity for autonomy, whose exercise is simply temporarily blocked. In normal circumstances, e.g. when she is not asleep, or in a coma, or sedated, she is capable of forming, revising, and pursuing a conception the good. By contrast, a young child lacks a well-developed capacity for autonomy. Although she might have the potential to develop such a capacity - if she has the necessary genetic or cognitive resources and if she receives an adequate education, in the adequate context or environment, etc. - she is currently incapable of forming, revising, and pursuing a conception the good. The difference between Betty and the child is thus that Betty is unable 
to make autonomous decisions just because her already developed capacity to exercise autonomy is temporarily hindered, whereas the child is unable to make autonomous decisions because as a child, she lacks the capacity for autonomy altogether.

I believe that this disanalogy is morally significant. The reason is that an individual who is temporarily unable to exercise her capacity for autonomy has a special interest in being treated in a way that she could retrospectively consent to, which an individual who does not possess such a capacity does not have. The interest in question is an interest in living one's life and being treated by others in accordance with, and in a way that respects, one's convictions and preferences about how to live and about what is valuable. Such an interest is thus grounded in the individual's possession of a (minimally developed) capacity to form, revise, and pursue a conception of the good. Hence, it is an interest that an individual who lacks such a capacity altogether does not possess. To put things differently, we can say that the interest in not having others setting goals for oneself, which is at the heart of the conception of autonomy-as-independence, is fundamentally grounded in the possession - at least to a minimal degree - of a capacity for autonomy in the achievement sense. It is an interest that one possesses because one has particular goals to begin with, and is capable (to a minimum degree) of rationally pursuing and identifying with them. ${ }^{11}$

This has important implications for the present case. For a start, it shows that young children or at least infants are not akin, from a moral point of view, to sleeping or unconscious people. Most importantly, the previous considerations support the conclusion that, although there may be a duty to respect the independence of temporarily unconscious individuals - a duty that requires us to make decisions for them that they can be expected to 
retrospectively consent to - there may be no corresponding duty to respect the independence of non-autonomous babies and young children. If so, unless the existence of such a duty can be vindicated in some other way, Clayton's argument by analogy fails to uphold the use of his principle of retrospective consent as a moral constraint on our treatment of very young children. ${ }^{12}$ If so, then Clayton's claim that practices such as, for example, the baptism of infants are always impermissible loses some plausibility. ${ }^{13}$

\section{Comprehensive enrolment and the shaping of retrospective consent}

Suppose, for the sake of argument, that parents do have a duty to respect their young children's independence. There is another important issue that is worth considering. It concerns the exact formulation and implications of Clayton's test of respect for independence. As presented above, the principle of retrospective consent allows us to determine when an individual's independence is violated, by specifying a sufficient condition for independence violation. Ideally, however, a complete test of respect for independence should also allow us to determine when an individual's independence is not violated. How can this desideratum be satisfied?

A natural option - to which Clayton himself hints at times ${ }^{14}$ - consists in formulating the principle of retrospective consent in a bi-conditional, rather than a conditional, form. Accordingly, we can say that an individual's independence is violated if, and only if, the person deciding for her cannot reasonably expect that the individual will retrospectively consent to the decisions that are made for her, while she is unable to autonomously decide for herself. This is equivalent to saying that having reasonable expectations about an 
individual's retrospective consent is both necessary and sufficient for respecting her independence. Let us call this 'the principle of retrospective consent*'. At first sight, this principle seems quite plausible. In what follows, however, I will argue that, when it is applied to children, it generates counter-intuitive implications. ${ }^{15}$

As a starting point, consider premise (4') of Clayton's argument. As we have seen, this premise states that parents cannot reasonably expect their children to retrospectively consent to having been raised according to their conception of the good, since they do not know whether their children will actually endorse their conception of the good. This premise can be challenged. The main problem with it is that it fails to take into account the fact that retrospective consent can be shaped by education. If parents do a good job at comprehensively enrolling their children into their conception of the good, it is indeed highly likely that the latter will later consent to how they were educated. So, if parents can reasonably be confident that they will be successful at transmitting their conception of the good to their children by enrolling them into it, then they can also reasonably expect that their children will retrospectively consent to their enrolment.

In addition to challenging premise (4'), these considerations put some pressure on the principle of retrospective consent*. When applied to children, the principle holds that if children can reasonably be expected to retrospectively consent to the decisions that are made for them, then their independence is not violated. As we have seen, however, parents may form reasonable expectations about their children's retrospective consent by influencing consent through comprehensive enrolment. The principle of retrospective consent* thus entails that in this case children's independence is not violated. This 
conclusion seems counter-intuitive. If so, Clayton faces a dilemma. If he agrees that the previous conclusion is intuitively incorrect, then he must admit that the principle of retrospective consent* is not a good test of respect for independence. On the other hand, if he is unwilling to abandon the principle of retrospective consent*, then he must grant that comprehensive enrolment is, after all and all other things equal, morally permissible, since it passes the test of respect for independence. ${ }^{16}$

\section{An anti-perfectionist argument in favor of comprehensive enrolment}

A possible response to the previous dilemma consists in revising the principle of retrospective consent* by combining it with a more demanding and idealized account of what counts as a 'reasonable expectation'. Clayton's earlier work, which draws explicitly on Rawls's conception of political legitimacy, offers a promising suggestion. Clayton maintains that parents ought to educate their children in ways that could be justified on the basis of public (or what I will call anti-perfectionist) reasons ${ }^{17}$ in the Rawlsian sense, that is, reasons that any reasonable person could accept no matter what conception of the good she endorses. ${ }^{18}$ Simply put, in negative terms, these are reasons that do not appeal to, or presuppose, the truth of any particular conception of the good or controversial philosophical, moral or religious ideal. In light of this, Clayton may say that parents' expectations about their children's retrospective consent count as reasonable if, and only if, there exists an anti-perfectionist justification in support of their educational decisions.

Let us call the resulting principle 'the anti-perfectionist principle of retrospective consent*'. This principle implies that, in order to determine whether comprehensive enrolment 
respects children's independence, we must determine whether there exists an antiperfectionist justification in favor of comprehensive enrolment, which can appropriately ground parents' expectations about their children's retrospective consent. ${ }^{19}$ Clayton believes that no such justification exists. In this section, I will defend the opposite view. My argument is built around Brighouse and Swift's account of the ethics of shaping children's values, which I will now sketch in its main lines.

According to Brighouse and Swift, in order for children's most fundamental developmental interests to best be met - including their interests in developing the capacities required for autonomy (-as-achievement) and for a sense of justice, as well as for regulating their emotions and connecting with others - they need to be engaged in an intimate and loving relationship with at least one parent. Brighouse and Swift further argue that an intimate and loving relationship unavoidably involves some degree of what they call 'value-shaping'. The reason is that some value-shaping is an inevitable by-product of value-sharing. In turn, value-sharing is required by two important ingredients of a successful loving and intimate parent-child relationship: spontaneity and authenticity.

Spontaneity and authenticity are crucial for a good parent-child relationship for two main reasons. The first is that children need close and loving role models to meet their developmental needs. Parents who make educational decisions 'robotically', without spontaneity and authenticity, are unlikely to inspire identification. The second, and perhaps most important, reason is that parents can hardly experience their relationship with their children as a source of joy and fulfillment without 'being themselves' in the relationship. In fact, children benefit most from their relationship with their parents when their parents 
perceive it as rewarding. Thus, it is in children's own interest that their parents experience the relationship with them as a source of meaning and joy (Brighouse and Swift 2014, pp. 153-155).

Brighouse and Swift are aware that value-shaping is not always an unintended effect of value-sharing. Some parents deliberately seek to shape their children's values in light of their own particular convictions. In other words, they seek to comprehensively enroll them into their conception of the good. Brighouse and Swift hold, however, that some deliberate value-shaping is crucial to intimacy because the sustainability and depth of any intimate relationship demand that the parties share some common interests and values. According to them, this supports a limited parental right to deliberately shape their children's values in light of their own, for two reasons. First, in early years, only parents can supply the values to be shared in the relationship, since young children do not yet have values of their own. Second, children's emerging value-commitments are typically much more plastic than those of adults. So, parents can legitimately give some priority to their own values in exercising their authority - even when children begin to develop their own values and interests. $^{20}$

Although Brighouse and Swift appear to be skeptical about the idea that there is a parental duty to respect children's independence - at least as Clayton understands it - I believe that their account can be used to show precisely that, under certain conditions, comprehensive enrolment does pass the test of respect for independence, as defined by the antiperfectionist principle of retrospective consent*. Indeed, Brighouse and Swift's account supports the following line of thought. Children's most fundamental developmental 
interests, including their interest in developing a capacity for autonomy, are best met when they are engaged in an intimate and loving relationship with at least one parent. As we have seen, an intimate and loving relationship requires some deliberate value-shaping. So, children's most fundamental developmental interests are best met when they are engaged in a parent-child relationship that involves some deliberate value-shaping. If this is true, however, there exists an anti-perfectionist justification for deliberate value-shaping. The reason is that any reasonable person could recognize, no matter what particular conception of the good she endorses, that she, as a child, had a fundamental interest in fully developing her capacity to adopt, pursue and revise a conception of the good. ${ }^{21}$ Yet, if the development of such a capacity is tied, in the way just described, to some deliberate parental valueshaping, then that person can also reasonably be expected to retrospectively consent to having been subject to such deliberate value-shaping, no matter what conception of the good she endorses.

One objection against this argument concerns its scope. One may argue that the previous argument vindicates, at most, some very mild forms of deliberate value-shaping, but not more 'global' forms of comprehensive enrolment, such as enrolment into a particular religion. The underlying thought is that comprehensive enrolment of this kind is never necessary for the development of a good, intimate and loving, parent-child relationship. It is perhaps very costly for some parents to refrain from engaging in it. However, by itself, this does not give a reason to the child to later consent to how she was educated.

Three things can be said in response. First, even if we granted this objection, the previous argument would still reach some significant conclusions, considering that Clayton deems to 
be impermissible any parental action deliberately aimed at passing on specific convictions on issues like sexuality, work, life-style, or religion. Second, arguably, in particular cases, some parental efforts to comprehensively enroll their children into their conception of the good may in fact be necessary for developing a close parent-child relationship. For some parents - perhaps especially religiously committed parents - comprehensively enrolling their children, e.g. by baptizing them, bringing them to church and teaching them the value of things like spirituality, or family ties, or love, as they understand it in light of their religious view, may not only be an important source of fulfillment and joy, but also a key and indispensible element of what it means for them to be authentic in building a connection with their children. Third, it is in any case not clear that comprehensive enrollment must be necessary for developing a close parent-child relationship, in order to elicit children's retrospective consent. More specifically, it is not unreasonable to think that a child may retrospectively consent to comprehensive enrolment when, and because, the latter facilitates, at least to some non-negligible degree, the development of an intimate relationship with her parents, one that serves her own fundamental developmental interests.

If these considerations are on the right track, then they offer a direct confutation of Clayton's argument. In particular, they show that, if the anti-perfectionist principle of retrospective consent* is the correct way to determine whether or not parents' educational decisions respect their children's independence, then at least some forms of comprehensive enrolment are, all other things equal, morally permissible. Having said this, it is worth emphasizing that the previous considerations vindicate only a conditional and limited moral permission for parents to engage in comprehensive enrolment - or to deliberately seek to shape their children's values in light of their own. The latter is permissible only when, and 
insofar as, it favors the development of parent-child intimacy in a way that serves children's 'neutral' developmental interests, including their interest in developing, and exercising, a capacity for autonomy-as-achievement. This suggests that, all other things equal, it is impermissible for parents to comprehensively enroll their children in ways that either undermine their future capacity to reject those values, or completely disregard their children's emerging capacity for autonomy during childhood.

\section{The problem of parents' intentions}

In the previous section, I argued that at least some limited forms of comprehensive enrolment are morally permissible, since they can be justified by appeal to antiperfectionist considerations. However, Clayton might not be persuaded. According to him, violations of independence involve a specific intention, namely, the intention to set another individual's goals. An adequate test of respect for independence should thus focus not just on whether there exists an anti-perfectionist justification in favor of the decision that are made for an individual, but also on whether the person deciding for that individual has appropriate aims.

Based on this, Clayton may present the following objection. Whenever parents comprehensively enroll their children into their conception of the good, they have the intention to deliberately shape their children's values. But the intention to deliberately shape children's values necessarily involves the intention to set children's ends or to decide for them which goals they should pursue. In Clayton's own terms, when parents are 'motivated by adherence to a particular comprehensive view', then, no matter the content of 
their comprehensive view, their conduct involves the assertion of a right to determine one's child's goals' (Clayton 2012, p. 363). If this is true, then comprehensive enrolment violates children's independence.

This objection against comprehensive enrolment is particularly strong. It implies that comprehensive enrolment is morally objectionable even when it is conducive to meeting children's fundamental developmental interests. Indeed, insofar as parents have the intention to set their children's ends, then the latter cannot reasonably be expected to consent to their parents' decisions, for these decisions evidence a lack of recognition of their independence. In what follows, however, I will argue that this objection can be resisted. More specifically, I will suggest that deliberately seeking to shape children's values does not necessarily involve the assertion of a right to fix their ends.

My starting point is the claim that it is possible for 'comprehensively motivated' parents those who make parenting decisions in light of their particular comprehensive (e.g. religious) convictions - to be genuinely and strongly committed to the development of their children's autonomy-as-achievement. As a matter of fact, many comprehensively motivated parents (religious and non-religious) do assign great value to autonomy, for their own particular comprehensive reasons. Yet, if parents are genuinely committed to promoting the development of their children's autonomy, then they are also committed to the idea that their children should be able to decide for themselves which goals to pursue, as they develop their ability to do that. But if they believe that their children should decide for themselves, then they are also committed to recognizing that they have no right to fix their ends for them. ${ }^{22}$ 
It is true that when a parent baptizes her child, or brings her to church, or teaches her to appreciate art, she intends to increase the likelihood that her child will come to understand and appreciate the values associated with, respectively, a religious faith and artwork. But when such a parent assigns great value to autonomy and is genuinely committed to the development of her child's autonomy, then, while seeking to shape her child's values, she remains open to (and in fact cultivates) the prospect that her child might endorse a different set of values. If this is true, then a comprehensively motivated parent can have the intention (or aim) to shape her child's values without also having the intention to set her ends or to decide for her.

These considerations allow us to clarify a related aspect of Clayton's position. In his earlier work, he distinguishes the attitude of actively seeking to make it the case that one's child comes to endorse certain values or ends (i.e. the attitude which I referred to as the intention to deliberately shape children's values) from the attitude of hoping that this will be the case. ${ }^{23}$ He thinks that the former is morally impermissible, but the latter is not. As we have seen, however, Clayton fails to recognize that seeking to impart comprehensive convictions does not necessarily involve deciding for one's child which ends she should pursue. Given this, Clayton also fails to recognize that a parent's intention to shape her child's values can sometimes be combined with the hope that her child will come to endorse certain values. In fact, this combination is precisely the one that best characterizes the attitudes of a comprehensively motivated parent who greatly values autonomy and is deliberately committed to developing her child's autonomy. 
This suggests that, contrary to what Clayton maintains, the attitude of seeking to impart comprehensive convictions in one's child is not morally objectionable in itself. Such an attitude is impermissible when it is combined with the intention to set one's child's ends; but it is permissible when it is combined just with the hope that one's child will adopt one's values as her ends. This is, of course, simply another way to say that autonomy-friendly forms of comprehensive enrolment are, all other things equal, morally permissible.

\section{Conclusion}

In this paper, I argued that Clayton's arguments against comprehensive enrolment are vulnerable to some serious objections. I also argued that, under certain conditions, some forms of comprehensive enrolment are morally permissible by (what I take to be) Clayton's own lights. More specifically, drawing on Brighouse and Swift's account, I showed that comprehensive enrolment can pass Clayton's retrospective consent test when it is conducive to a good, loving, spontaneous and authentic, parent-child relationship, which serves the developmental interests of the child and, in particular, the development of her capacity for autonomy.

\section{Acknowledgements}

I am especially grateful to Jonathan Quong and Mauro Rossi for very useful suggestions and feedback on previous versions of the paper. I would also like to thank Harry Brighouse, Christine Tappolet, Sarah Stroud, Christine Sypnowich, Kristin Voigt, Daniel Weinstock and Danielle Zwarthoed for helpful comments and discussions on issues addressed in the paper. This project has received funding from the European Research Council (ERC) under the European Union's Horizon 2020 Research and Innovation programme [Grant Agreement Number: 648610]. 


\section{Notes}

${ }^{1}$ For simplicity, in what follows I will mainly talk about 'comprehensive enrolment'. I will use this term to refer to the idea of seeking to impart in children a more or less comprehensive set of particular controversial commitments or beliefs about the value of certain activities and aims.

${ }^{2}$ I will not take position on the further question of whether parents have a (conditional and limited) right to comprehensively enrol their children into their conception of the good.

${ }^{3}$ Clayton (2006) explicitly builds his arguments against children's comprehensive enrolment on the second and the third premises. Brighouse and Swift (2014) agree with these claims (although not with Clayton's conclusion). In my view, these are not simply premises in Clayton's arguments; rather, they are, together with (1), the basic assumptions framing the debate.

${ }^{4}$ Unless, of course, the choice of the meal is value-laden.

${ }^{5}$ Clayton calls this the 'instrumental argument'. See Clayton 2006, p. 106.

${ }^{6}$ For this reason, I believe that the argument is best understood as an argument from autonomy-asachievement.

${ }^{7}$ See Clayton 2012, pp. 359-361.

${ }^{8}$ For simplicity, from now on I will omit this qualification.

${ }^{9}$ My reconstruction is mostly based on Clayton's 2012 paper, in which he specifies and defends his view in response to Christina Cameron's (2012) objections.

${ }^{10}$ See Clayton, 2012.

${ }^{11}$ For a similar line of thought, see Bou-Habib \& Olsaretti 2015, p. 23.

${ }^{12}$ Notice that my argument does not imply that it is permissible for parents to ask doctors to perform nose jobs (or other similar surgeries) on infants unable to give their informed consent, in order to fix their body according to their esthetic preferences or religious beliefs. Indeed, there are 
many reasons for thinking that interventions of this type are morally problematic. For one, they are very invasive, medically risky and painful, which implies that they are very likely to have a significant negative impact on the child's current and future wellbeing. They also violate bodily integrity, which - we may think - children have an interest in even before they begin to develop a capacity for autonomy. In addition, in certain cases such interventions may also undermine the child's future autonomy, for instance by limiting her options in a morally unacceptable way (e.g. the option of enjoying sex in the case of female circumcision). These are just a few considerations showing that the absence of an obligation to treat infants and young children according to the principle of retrospective consent does not have obvious counter-intuitive implications. These considerations also show that Clayton's nose job example is over-determined.

${ }^{13}$ This remains compatible with the idea - which Brighouse and Swift endorse - that parents have a duty not just to promote the development of their child's future autonomy, but also to respect their children's emerging autonomous commitments and interests. This is different, however, from saying that they have a duty to respect the independence of non-autonomous children, as Bou-Habib \& Olsaretti (2015) have also noted.

${ }^{14}$ See Clayton 2012, pp. 257-258.

${ }^{15}$ I thank Jonathan Quong for suggesting to me the line of thought developed in this section.

${ }^{16}$ A possible reply to this objection consists in saying that, in the previous case, it is not children's independence that is violated, but the demands of autonomy-as-achievement. According to this line of thought, the fact that parents can reasonably expect their children to retrospectively consent to their enrolment is indeed sufficient to ensure that their independence has been respected. Yet, by comprehensively enrolling their children in such a way as to significantly increase the likelihood of their retrospective consent, parents fail to ensure the proper development of their children's autonomy-as-achievement. This implies that, while the principle of retrospective consent* offers a good test of respect for independence, it needs to be complemented with a test concerning respect 
for autonomy-as-achievement. (For a similar reply, see Bou-Habib \& Olsaretti 2015, fn. 10, pp. 2223.)

It is not clear, however, that this reply succeeds. For a start, it does not seem to offer a correct diagnosis of the case in question. According to Clayton's characterization, manipulating children's goals is a paradigmatic instance of independence violation, not of autonomy-as-achievement violation. In addition, the reply seems to have a limited scope. Indeed, it does not seem impossible for parents to increase the likelihood of children's future consent through comprehensive enrolment, while, at the same time, satisfying the demands of autonomy-as-achievement. For instance, parents might educate their children in a way that significantly increases the cost of rejection of their conception of the good, while making sure they also develop their capacity for autonomy to a sufficient degree. (Notice that this remains compatible with the considerations put forward in the section on the cost of rejection.)

${ }^{17}$ Clayton calls this the 'public reason restriction'. See Clayton 2006, p. 93.

${ }^{18}$ A reasonable person, according to Rawls (1993, pp. 49-60), is a person who is committed to the idea of society as a fair system of cooperation between free and equal persons and who recognizes the existence of reasonable disagreement about the good.

${ }^{19}$ If an anti-perfectionist justification exists, then children can reasonably be expected to consent to the decisions that are made for them independently of the conception of the good that they presently endorse, since an anti-perfectionist justification is one that any reasonable person could accept.

${ }^{20}$ Yet, as suggested in fn. 13, parents are also under a duty to eventually try and adapt to their children's own evolving values and interests by engaging with them in a respectful and openminded way (see Brighouse and Swift 2014, p. 156).

${ }^{21}$ In the same way, she could recognize that she had an interest in developing a sense of justice and an ability to regulate her emotions and to emotionally connect with others. These interests are not tied to any particular conception of the good. 
${ }^{22}$ It seems reasonable to guess that many comprehensively motivated parents would refuse to give their children a 'value-determining pill' which would make it the case - as Brighouse and Swift (2014, p. 162) imagine it - that their children end up endorsing their conception of the good. I take this to support my claim.

${ }^{23}$ Clayton writes: 'We must distinguish between an individual's hope that someone else comes to affirm her atheism, say, and her seeking to make it true (or more likely) that he does' (Clayton 2006, p. 115).

\section{References}

Brighouse, H. and Swift, A., 2014. Family Values: The Ethics of Parent-Child Relationships. Princeton: Princeton University Press.

Cameron, C., 2012. Debate: Clayton on Comprehensive Enrolment. Journal of Political Philosophy, 20 (3): 341-352.

Clayton, M., 2006. Justice and Legitimacy in Upbringing. Oxford: Oxford University Press.

Clayton, M., 2012. Debate: The Case Against the Comprehensive Enrolment of Children. Journal of Political Philosophy, 20 (3): 353-364.

Clayton, M., 2015. Anti-Perfectionist Childrearing. In: A. Bagattini and C. Macleod, eds. The Nature of Children's Well-Being. Dordrecht: Springer, pp. 123-140.

Bou-Habib, P. \& Olsaretti, S. 2015. Autonomy and Children's Well-Being. In: A. Bagattini and C. Macleod, eds. The Nature of Children's Well-Being. Dordrecht: Springer, pp. 15-34.

Rawls, J., 1993. Political Liberalism (Expanded Edition). New York: Columbia Classics in Philosophy. 